\title{
Zohreh Zehbari, Reza Mehr Afarin, Seyyed Rasul Musavi Haji. «Studies on the Structural Characteristics of Achaemenid Pottery from Dahan-E Gholaman »
}

\section{Rémy Boucharlat}

\section{OpenEdition}

\section{Journals}

Édition électronique

URL : http://journals.openedition.org/abstractairanica/47273

DOI : $10.4000 /$ abstractairanica. 47273

ISBN : 1961-960X

ISSN : 1961-960X

Éditeur :

CNRS (UMR 7528 Mondes iraniens et indiens), Éditions de l'IFRI

\section{Référence électronique}

Rémy Boucharlat, «Zohreh Zehbari, Reza Mehr Afarin, Seyyed Rasul Musavi Haji. «Studies on the Structural Characteristics of Achaemenid Pottery from Dahan-E Gholaman » », Abstracta Iranica [En ligne], Volume 37-38-39 | 2018, document 92, mis en ligne le 30 décembre 2018, consulté le 26 septembre 2020. URL : http://journals.openedition.org/abstractairanica/47273 ; DOI : https://doi.org/ 10.4000/abstractairanica.47273

Ce document a été généré automatiquement le 26 septembre 2020.

Tous droits réservés 


\title{
Zohreh Zehbari, Reza Mehr Afarin, Seyyed Rasul Musavi Haji. «Studies on the Structural Characteristics of Achaemenid Pottery from Dahan-E Gholaman »
}

\author{
Rémy Boucharlat
}

\section{RÉFÉRENCE}

Zohreh Zehbari, Reza Mehr Afarin, Seyyed Rasul Musavi Haji. « Studies on the Structural Characteristics of Achaemenid Pottery from Dahan-E Gholaman », ANES, 52, 2015, p. 217-259

Les fouilles italiennes du site achéménide de 1962 à 1966 ont donné lieu à quelques articles seulement du fouilleur, puis de Bruno Genito dont l'un sur la céramique, enfin de Giulio MARESCA dans les Proc. of the 6th ICAANE, 2010. De même les travaux plus récents de S.M.S. Sajjadi, depuis 1999, ont été très publiés. Il faut donc saluer cette étude, bien que le sujet soit restreint à la poterie, ajoutant la poterie conservée sur place ou à Zabol, et provenant majoritairement de l'un des grands bâtiments érigés le long du canal principal. Les A. ont mené une étude technique de la poterie, de la décoration incisée (motifs anthropomorphes) assez peu fréquente, et construit une typologie détaillée, accompagnée de comparaisons avec des sites contemporains dans l'ensemble de l'Iran. Les fouilleurs italiens pensaient que le site était rapidement abandonné après le début de la période achéménide (VIe - Ve s. av.n.è.), tandis que les A. proposent une occupation pendant toute la période et même encore au début de la période séleucide, avant un abandon progressif. Ce processus reste inexpliqué, de 
même que la fonction du site avec ses nombreux grands bâtiments n'a pas été élucidé, malgré l'hypothèse d'un site très particulier, peut-être un centre satrapique.

\section{AUTEURS}

\section{RÉMY BOUCHARLAT}

UMR 5133 CNRS-Université de Lyon 